ANNALES

UNIVERSITATIS MARIAE CURIE-SKŁODOWSKA

LUBLIN - POLONIA

VOL. LXVII, 1-2

SECTIO AA

2012

\title{
Some aspects on the history of thermal analysis
}

Erich Robens ${ }^{a}$ and Shanath Amarasiri A. Jayaweera ${ }^{b}$

${ }^{a}$ Schlesierstraße 5, D-61381 Friedrichsdorf, Germany.

Formerly: Battelle-Institut e.V., Frankfurt am Main, Germany, erich.robens@t-online.de

${ }^{b} 42$ Tanton Road, Stokesley, Middlesbrough, TS9 5HR, UK, Formerly: Teesside University,

School of Science \& Engineering, Middlesbrough, UK, saajayaweera@yahoo.co.uk

The short survey covers invention and development of thermal and related analytical methods: calorimetry, thermoporometry, dilatometry, thermogravimetry, sorptometry, hygrometry.

\section{INTRODUCTION}

Analytical methods include very often thermal treatment of the sample. Thermal analysis usually covers a group of very different methods in which the temperature is a central parameter.

1. Calorimetry

2. Thermoporometry

3. Dilatometry

4. Thermogravimetry

5. Sorptometry, hygrometry

In the true sense thermal analysis covers calorimetry, dilatometry and thermoporometry in which the influence of temperature on the sample is directly recorded. The other methods are often complementary: gas release or uptake as a function of temperature and gas pressure. At any 
rate either the temperature is changed as a function of time whereas pressure of the surrounding gas or vacuum is kept constant or temperature is kept constant and the gas pressure is varied. Because at all of these investigations the response on a change of the influence proceeds slowly quasi-isothermal measurements may be made. To avoid measurements lasting several weeks measurements may be broken off before equilibrium is attained and its value calculated by means of extrapolation methods [1-3].

Because small effects are to be measured with high sensitivity, the instruments, measuring procedure and evaluation methods are standardised [4-5]. Two journals are devoted especially to thermal analysis: Thermochimica Acta (Reed Elsevier, Amsterdam) and Journal of Thermal Analysis and Calorimetry (Springer Science + Business Media, Heidelberg and Akadémiai Kiadó, Budapest).

The history of those methods is very different. Though some roots reach down to middle ages or even antiquity, in general they are relatively recent, because the analytical branch of chemistry is likewise young. It begun simultaneously with development of modern chemistry a few hundred years ago. As starting event may be regarded the work of Lavoisier and others in his environment during the French Revolution (1789-1799). At that time also measuring instruments were developed with the required sensitivity which allowed investigating the small effects to be observed in thermal analysis.

\section{CALORIMETRY}

Calorimeters measure the quantity of heat energy involved in processes such as heating, chemical reactions, changes of state, and mixing of substances. Basic components are thermostat and temperature sensors. Measurements can be performed in different modes: adiabatic, heat balance, and heat flow. The instruments are very differently equipped with regard to the task of measurement. The Scottish physician and chemist Joseph Black (1728-1799) is said to be the founder of calorimetry. He was the first to recognize the distinction between heat and temperature, and introduced the concepts of latent heat and specific heat. The first known calorimeter is the ice-calorimeter, used in the winter of 1782-83, by Antoine Lavoisier and Pierre-Simon Laplace (Fig. 1). 


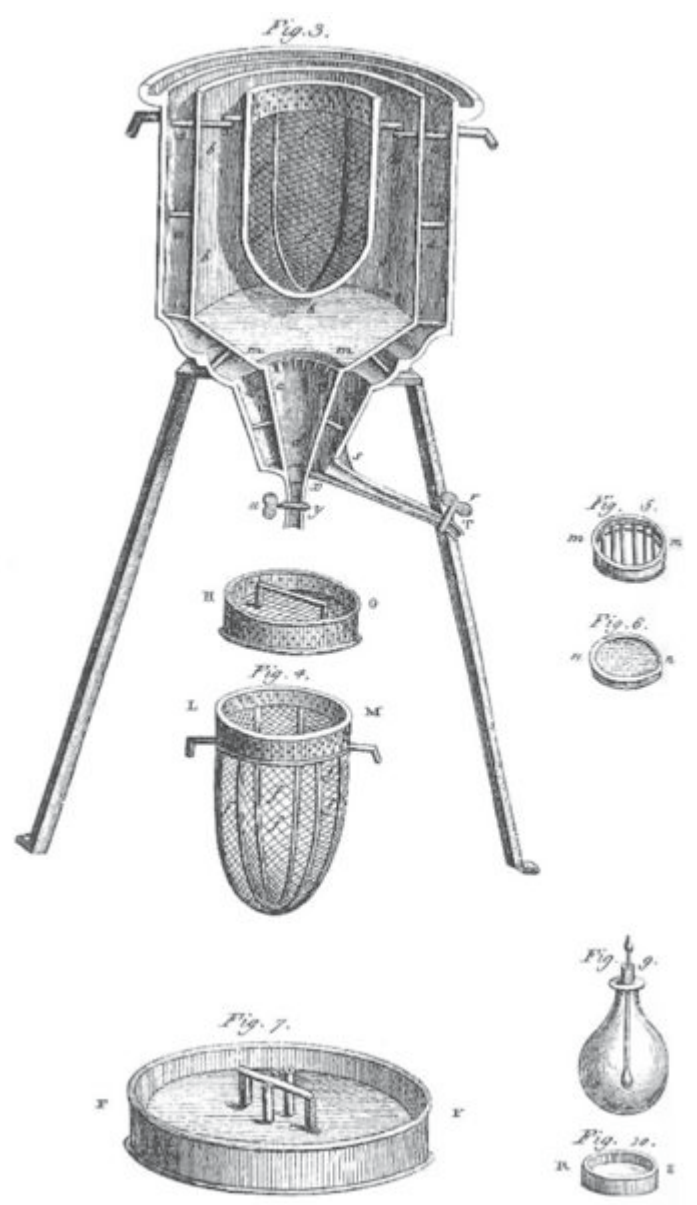

Fig. 1. Ice-calorimeter 1782 of Antoine Lavoisier and Pierre-Simon Laplace.

Considering the various tasks of heat measurements various types of calorimeters had been developed and they are operated in different modes: isothermal, adiabatic, heat flow, heat balance etc. Usually the sample is compared with a reference material.

The Tian-Calvet calorimeter is a differential scanning calorimeter based on a design of A. Tian 1923 [6] and improved by E. Calvet [7-9]. It is equipped with thermopiles according to Tian (Fig. 2).

Concerning such comparatively large calorimeters a recent development of a sensor gas calorimeter with high sensitivity was made in 2000 by J.U. Keller (Fig. 3) [10]. 

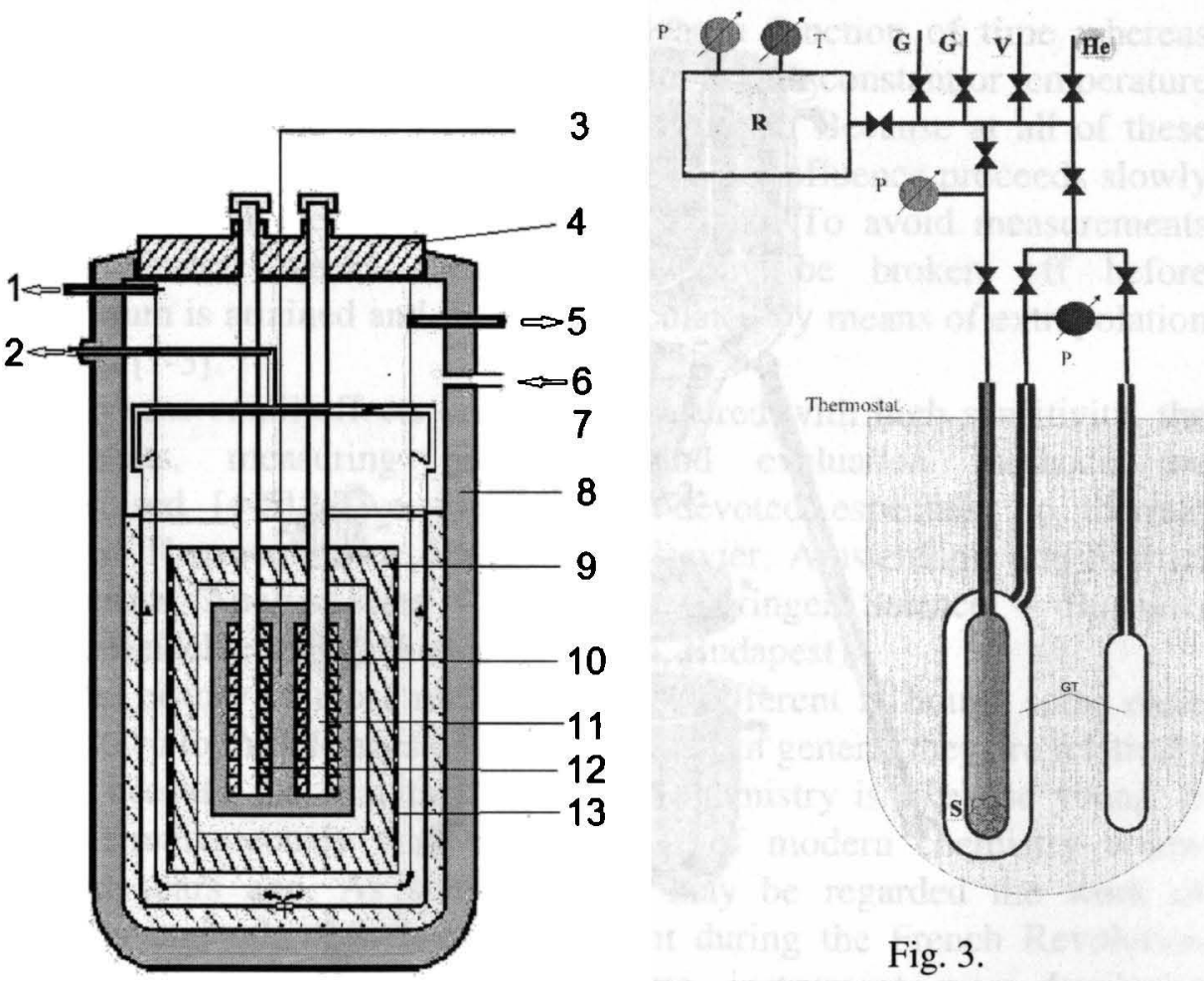

Fig. 3 .

Fig. 2.

Miniaturising calorimeters allowed for applications in various field of chemistry physics, and biology (Figs 4/5).

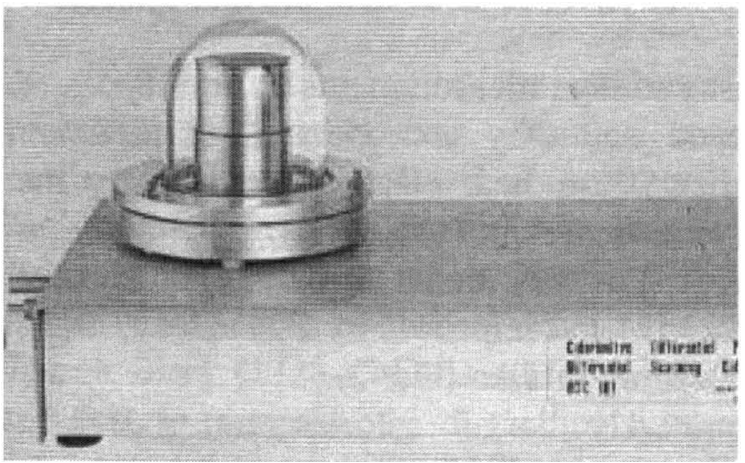

Figs 4. Differential scanning calorimeters DSC.

a) SETARAM, Caluire, France 1990. 

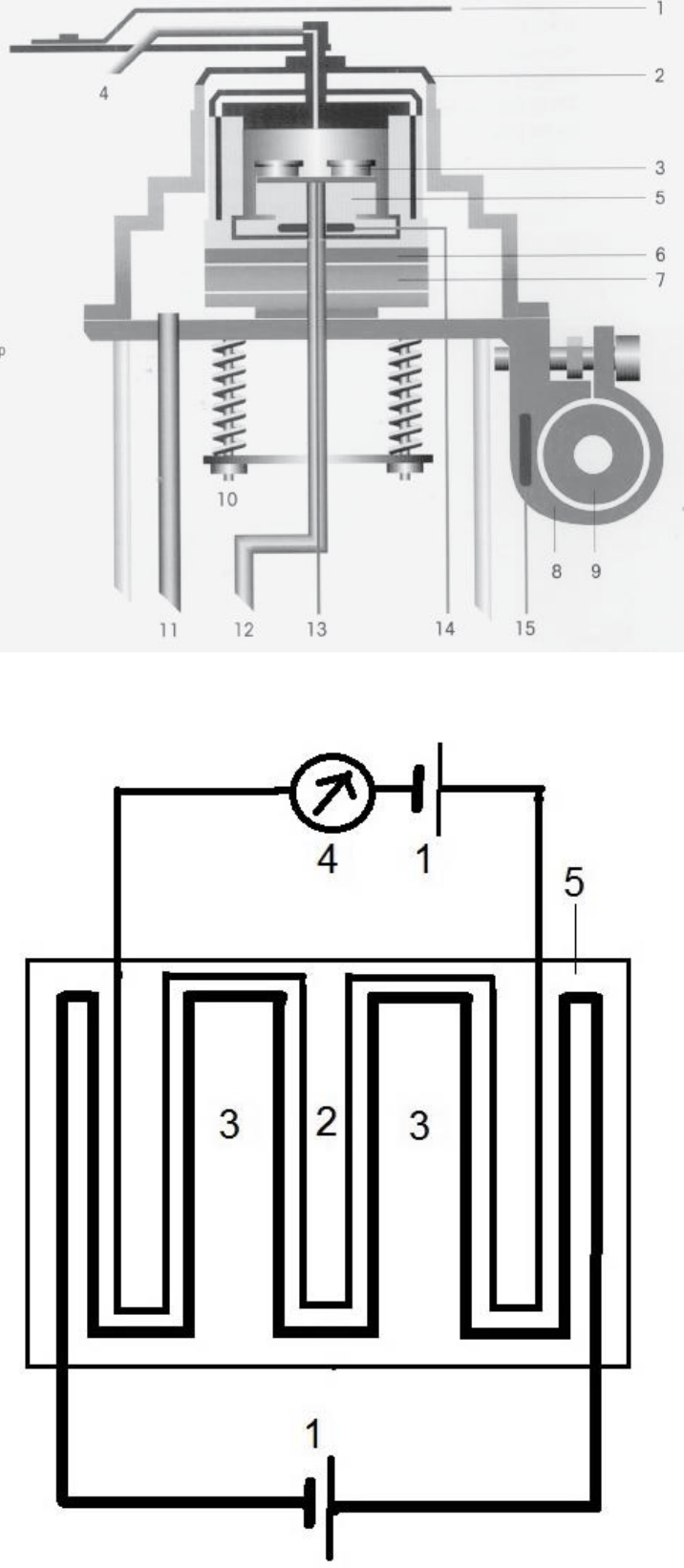

b) Mettler-Toledo, Greifensee, Switzerland

1 heat shield, 2 furnace lid, 3 crucibles with sample and reference on DSC sensor, 4 purge gas outlet with connection to vacuum pump, 5 silver furnace, 6 flat heater between two insulating disks, 7 thermal resistance cooler, 8 cooling flange, 9 cold finger, 10 compression spring construction, 11 dry gas inlet, 12 purge gas inlet, 13 DSC raw signal to ampli-fier, $14 / 15 \mathrm{Pt}$ temperature sensors.

Fig. 5. Diagram of the measuring cell of a mi-crocalorimeter. 1 electric power source 2 resistance thermometer (platinum) 3 heater (platinum) 4 current gauge 5 membrane (polycrystalline silicon with boron atoms implanted or a niobium-silicon alloy)

In particle physics, electromagnetic calorimeters (ECAL) are used to measure the energy of showers of particles like hadrons (neutrons, protons) that interact primarily via the strong nuclear force [11]. ECAL consists of lead tungstate crystals. In the LHD, CERN, Switzerland, the cylindrical 'barrel' consists of 61200 crystals formed into 36 
'supermodules', each weighing around three tonnes and containing 1700 crystals. The flat ECAL endcaps seal off the barrel at either end and are made up of almost 15000 further crystals. These high-density crystals produce light in fast, short, well-defined photon bursts that allow for a precise, fast and fairly compact detector. Special photodetectors are glued onto the back of each of the crystals to detect the scintillation light and convert it to an electrical signal that is amplified and analysed.

\section{THERMOPOROMETRY}

Thermoporometry is a calorimetric method for characterizing pore structure from the melting or freezing point depression of a liquid confined in a pore, by virtue of the added contribution of surface curvature to the phase-transition free energy [12]. In thermoporometry a liquid is imbibed into the porous sample, the sample cooled until all the liquid is frozen, and then warmed until all the liquid is again melted. The latent heat released or taken up is measured by a differential scanning calorimeter (Figs 4). The melting point depression is inversely proportional to the pore size which is calculated using the GibbsThomson equation [13]. This is the particular case for constant pressure of the Gibbs equation, whereas the Kelvin equation used in sorptometry is the particular case for constant temperature. The progress of freezing of a liquid in an inkbottle pore is sketched in Fig. 6. In the calculation of the pore size distribution a quasi liquid layer about two molecules thick, constantly remaining at the surface, should be considered. The method was invented in the $1970^{\text {th }}$ by M. Brun, A. Lallemand, J.-F. Quinson and C. Eyraud [14]. It results in the determination of pore size distribution and total pore volume and gives some information on the pore structure complementary to those from gas sorptometry. The pore size range, however, is more restricted [15-17].

Nuclear magnetic resonance cryoporometry (NMRC) is a technique originated in 1993 for measuring total porosity and pore size distributions [18-19]. 


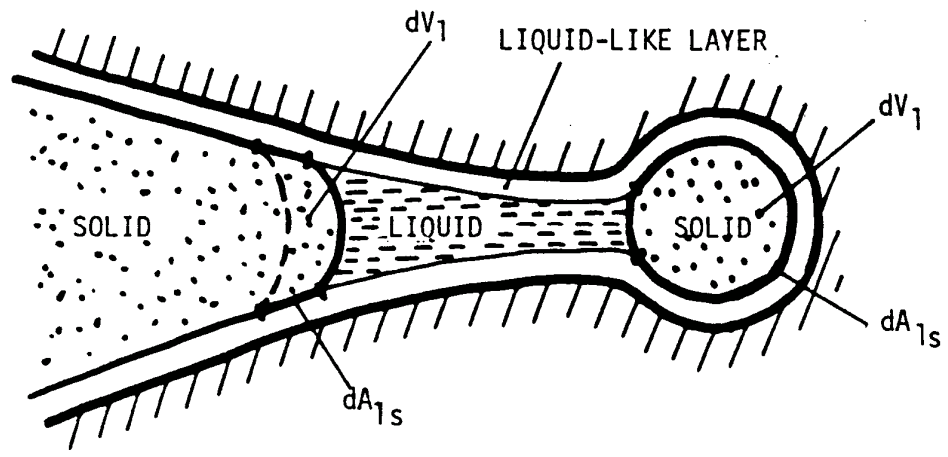

Fig. 6. Freezing progress of a liquid in an inkbottle pore during a thermogravimetric measurement.

\section{DILATOMETRY}

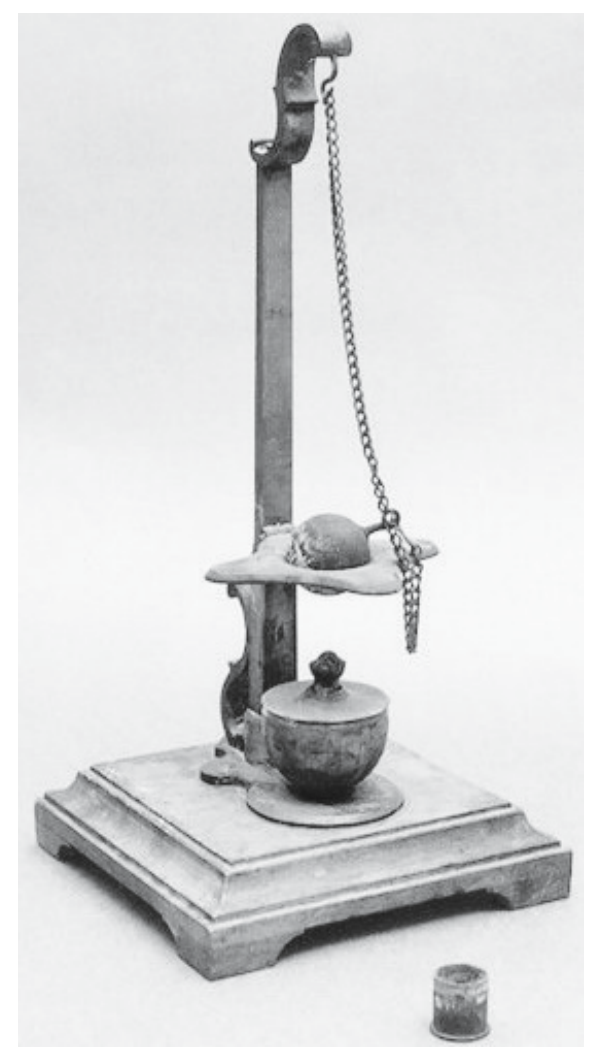

Fig. 7. The ring of Willem Jacob 's Gravesande.
The beginning of dilatometry is a demonstration of Willem Jacob's Gravesande (1688-1742) of a metal ball and a ring (Fig. 7) [20-21]. The ball can just pass the ring, both made of the same metal. When the ball is heated or the ring is cooled, it is retained.

Measurement of the expansion of liquids can be made by heating in pycnometer flasks. For gases alter-natively the displacement of a liquid may be measured by observing the increase in pressure similar to the arrangement of the gas calorimeter in Fig. 3. For temperatures up to $100^{\circ} \mathrm{C}$ heated water is fed through the tubular sample and the increase in length is measured by means of any type of position sensor. 
Such an arrangement can likewise be used to measure liquid expansion (Fig. 8a). For temperatures up to $\sim 2000^{\circ} \mathrm{C}$ in a pushrod dilatometer the rod-shaped sample is heated in a programmed oven and the increase in length measured by means of a position sensor (Fig. 8b). In capacitive dilatometers the sensor is a plate capacitor and length variations in the picometer range can be measured.

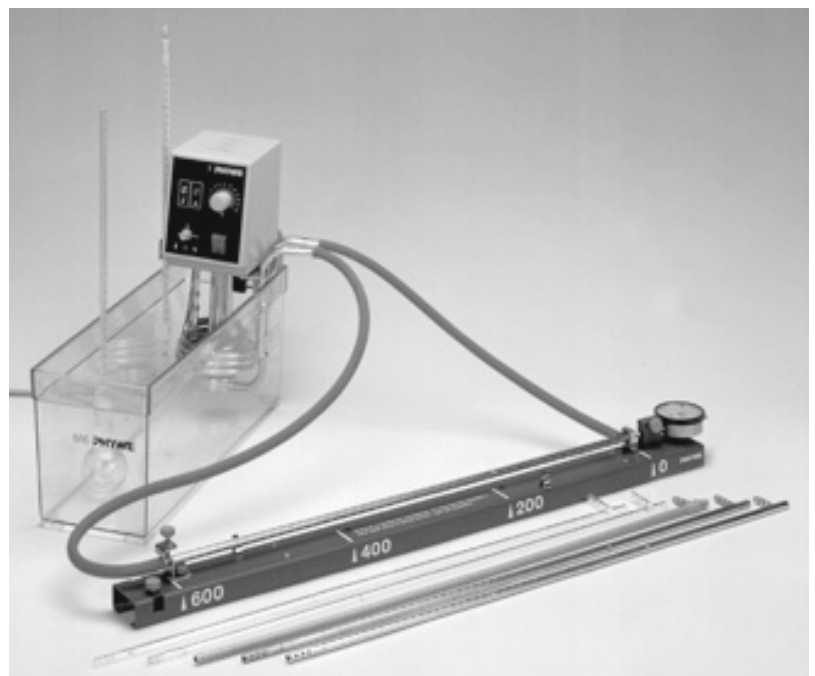

Fig. 8a. Dilatometer for liquids and solids. (๑ PHYWE Systeme GmbH und Co. KG, Göttingen, Germany.)

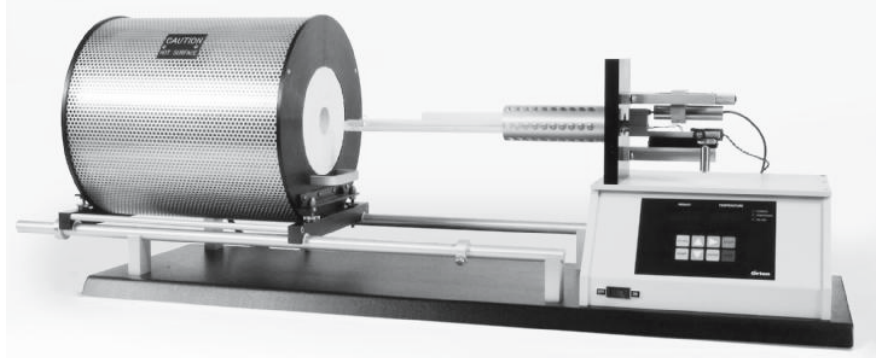

Fig. 8b. Pushrod dilatometer. (๔) Materials Research Laboratory, Institute of Physics and Electronics, University of Peshawar, Pakistan.

\section{SORPTOMETRY, HYGROMETRY}

In sorption experiments and hygrometry uptake or release of a gas or water vapour, respectively, are measured as a function of time, usually at constant temperature [22-23]. The first record of a water vapour 
adsorption experiment is found in the Bible. In the Book of Judges [24] we read,

"And Gideon said to God: If you want me to save Israel by my hand, as you said, behold, I put fresh sheared wool on the floor and if the dew falls only on the wool, and it will be dry at all the earth beside, than shall I know that you want to save Israel by my hand, as you have said. And it was so: When he got there in the early morning and wrung out the wool, he could press out the dew from the wool, a bowl full of water. After that Gideon said to God: Your anger should not flare out against me, if I speak again: Only once more I will try it with the wool: Only the wool shall be kept dry, and dew shall be upon all the ground. And God did so in the following night: The wool remained dry and the dew was on all the ground."

Gideon offended against the first law of experimental work: "Never repeat an experiment!" Indeed, the second run had the opposite result. And he draw very strange conclusions from its result: He started a war. Already Luther remarked that the description of the experiment is unclear. Nevertheless, there are plausible explanations for the inconsistent results [25-26].

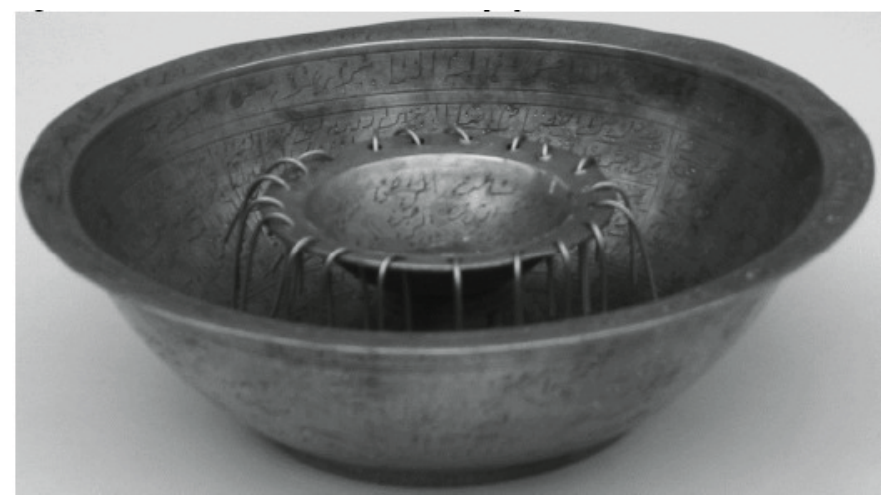

Fig. 9. 'The Doctor of Cairo' (dew sampler),

A strange volumetric device, which was in use until recently, should be mentioned: 'The doctor of Cairo' (Fig. 9). These artistic bowls served for dew sampling during cool nights. The condensed water was used for medical purposes. 
In the $15^{\text {th }}$ century weather forecasting became very popular. Measurements were made in order to determine atmospheric humidity. The very first to describe such an instrument [27], was the German cardinal Nicolaus Cusanus (1401-1463). In his book "Idiota de Staticis Experimentis", , that means "The layman about experiments with a balance" (Fig. 10) [28], he let this ignorant person, probably his mechanic, suppose,

"If anyone hangs on one side of a big balance with dry wool and loads of stone on the other side until equilibrium is established, at a place and in air of moderate temperature he could observe that with increasing humidity the weight of the wool increases and with increasing dryness of the air it decreases. By these differences it is possible to weigh the air and it is likely that one might perform weather forecasting."

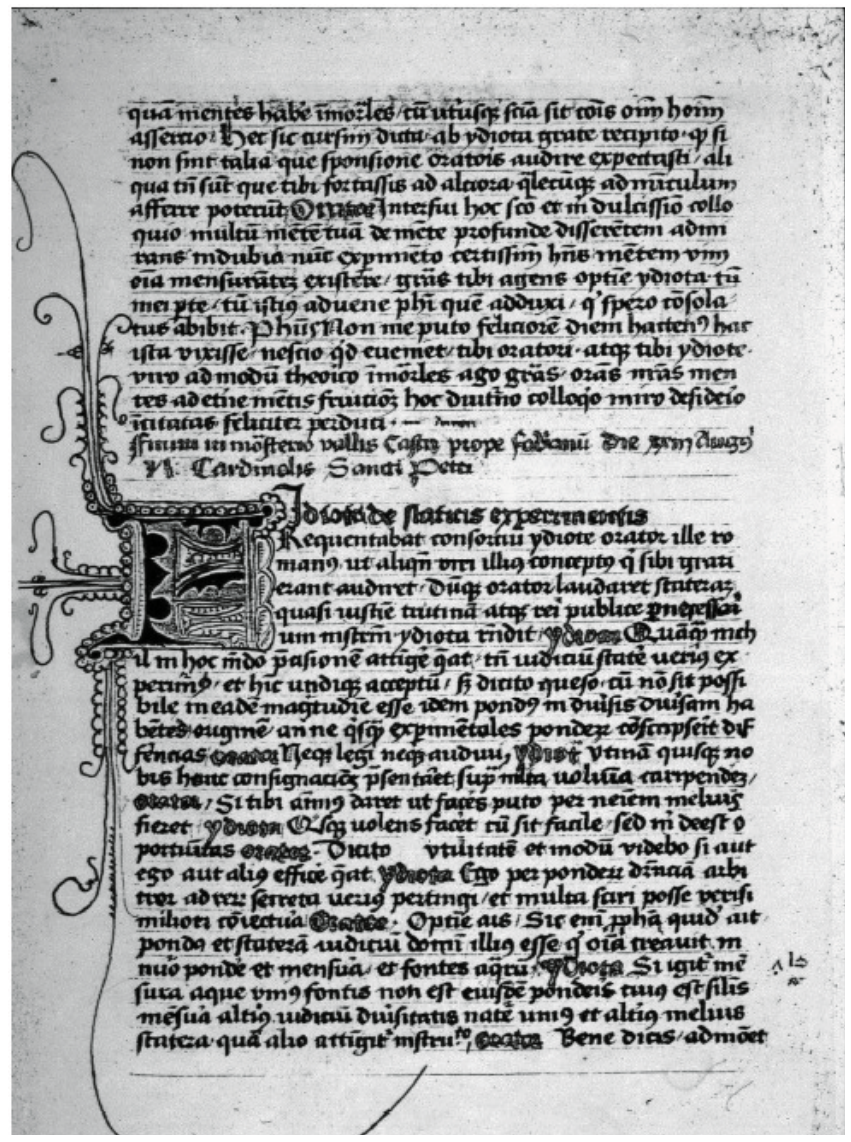

Fig. 10. Codex Cusanus (1450). Beginning of the Chapter "Idiota de Staticis Experimentis". 
About 20 years later the Italian architect and painter Leo Battista Alberti (1404-1472) described a similar device,

"We know, that a sponge becomes wet from atmospheric humidity and by this fact we make a balance with which we weigh the weight of the air and the dryness of the winds." [29].

From Leonardo da Vinci (1452-1519) we have three designs of inclination balances loaded with a sponge or with cotton (Fig. 11) [30-32]. With reflected face he added to the sketches,

"To recognize the quality and density of the air and to forecast rain."

and

"Means to detect, when the weather will break-up."

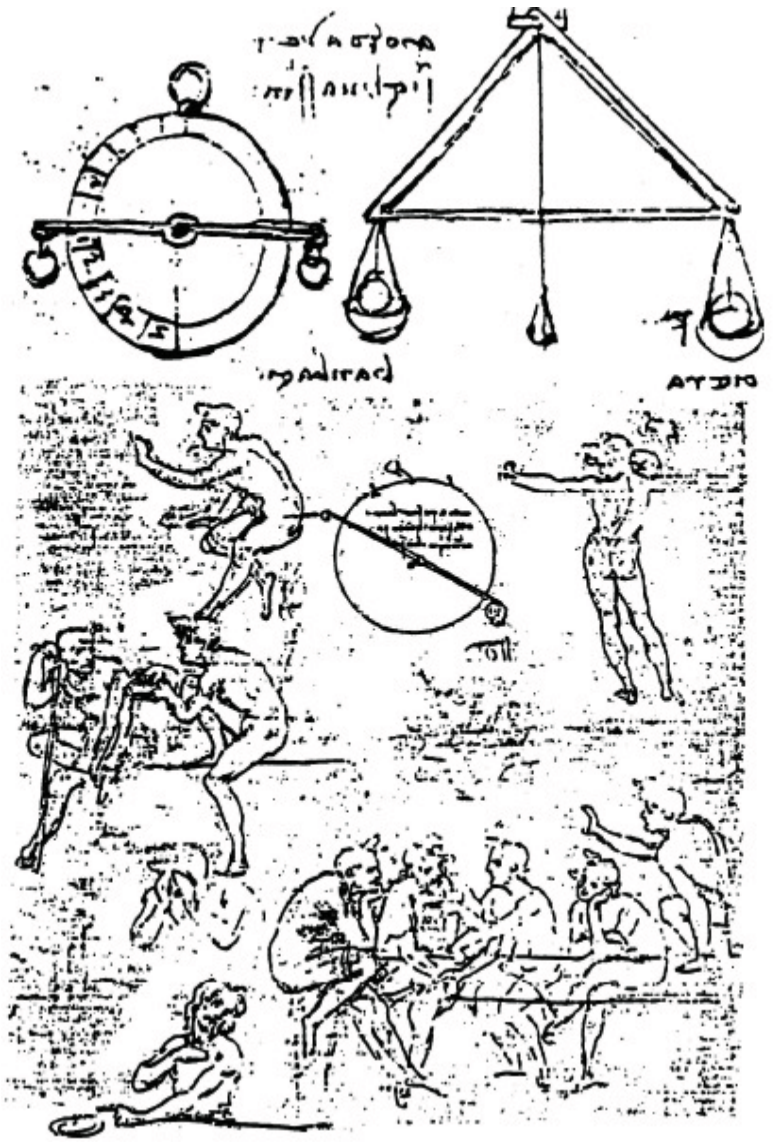

Fig. 11. Three sketches of gravimetric hygrometers/barometers of Leanardo da Vinci. 
In 1773, Scheele begun to investigate adsorption systematically (Fig. 12):

"I filled a little retort half with pretty dry grinded coal and tied up a bladder. As soon as the retort become hot, the bladder, expanded and when the bottom was glowing, the bladder was not expanding more. After that, I let cool down the retort, and the air returned from the bladder into the coal. the volume of air was about eight times of that of the coal."
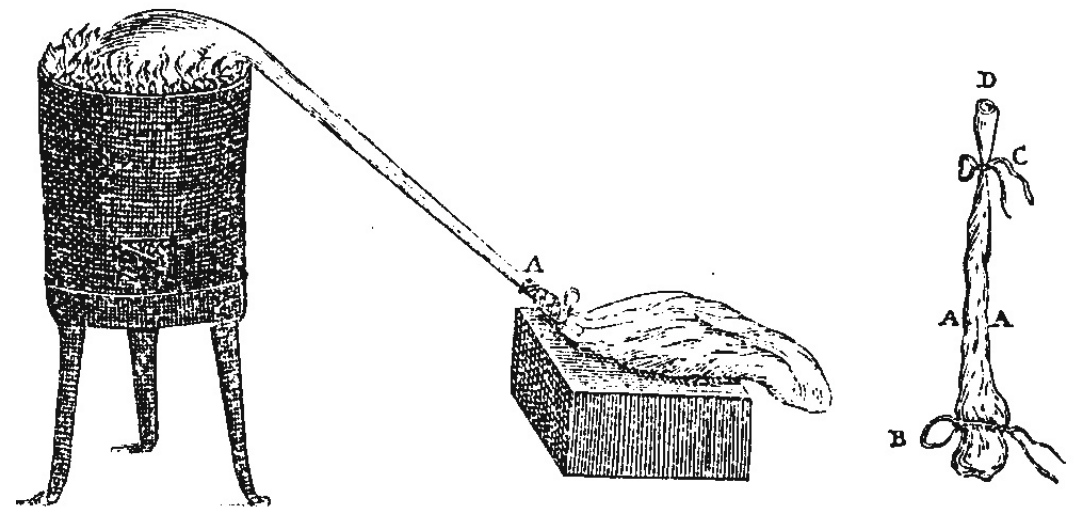

Fig. 12. Karl Scheele (1742-1786), Sorption apparatus Stockholm 1777. A is the bladder. The empty bladder is shown on the right hand side.

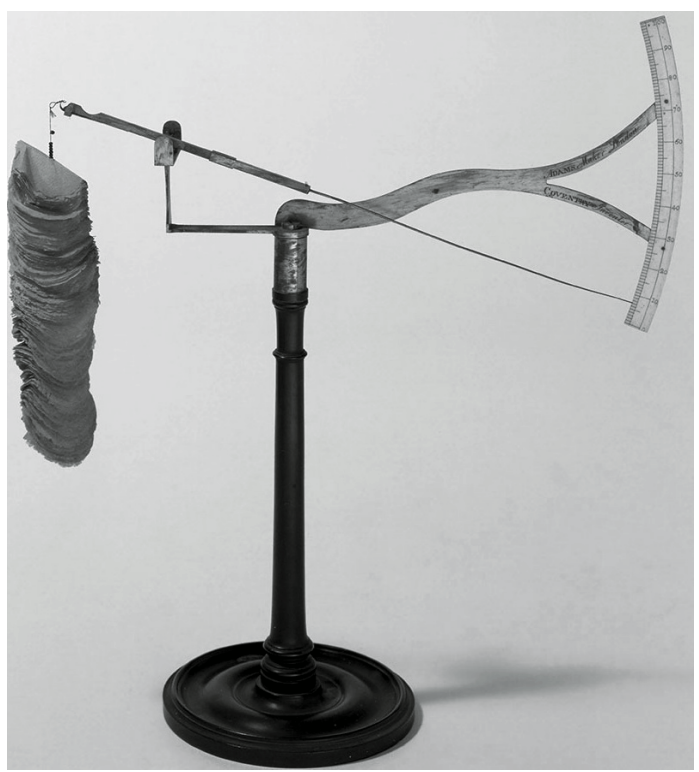

Fig. 13a. Adams paper disc hygrometer 18th century. Museo Galilei, Florence, Italy. 
Nearly simultaneously Priestley in England and Abbé Fontana in Italy investigated adsorption by introducing glowing charcoal through mercury into a reversed glass cylinder.

In the $18^{\text {th }}$ and $19^{\text {th }}$ century a variety of instruments for weather investigation had been designed [22, 33-35]; a few are presented in Figs 13. Henri Victor Regnault (1810-1878) determined air humidity simply by conveying an air stream through U-tubes filled with phosphorous pentoxide or calcium chloride and weighing. Gas adsorption isotherms were first measured and plotted by Chappuis (Fig. 14) and Kayser. The latter developed a first empirical isotherm equa-tion. The notation 'adsorption isotherm' seems to be created by Ostwald in 1885 .

Applying the principles the kinetic theory of gases - but nevertheless empirical - Langmuir in 1916 deduced the well-known equation for the Langmuir-isotherm.

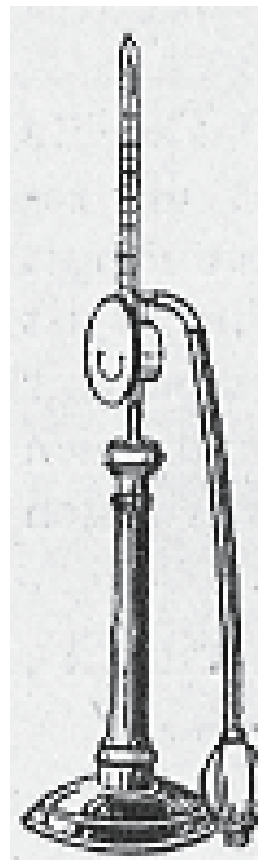

Fig. 13b. Lambrecht dew point hygrometer 1859 .

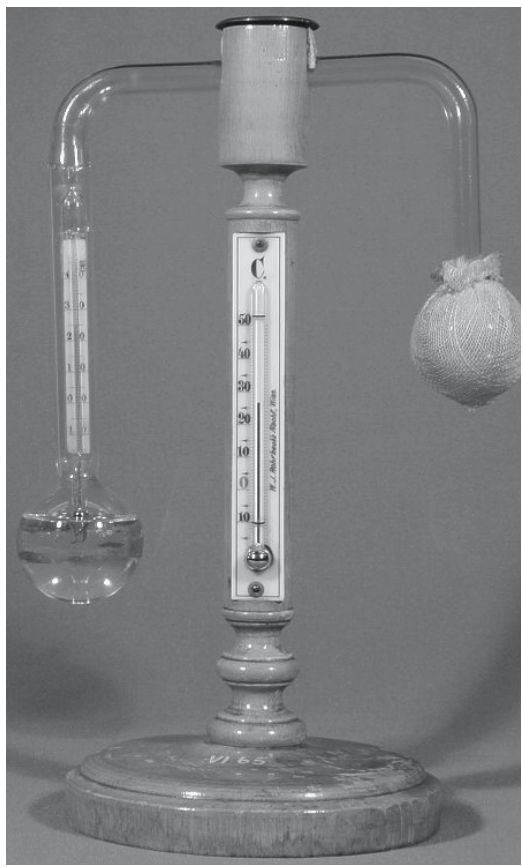

Fig. 13c. Daniell dew point hygrometer 1892. 


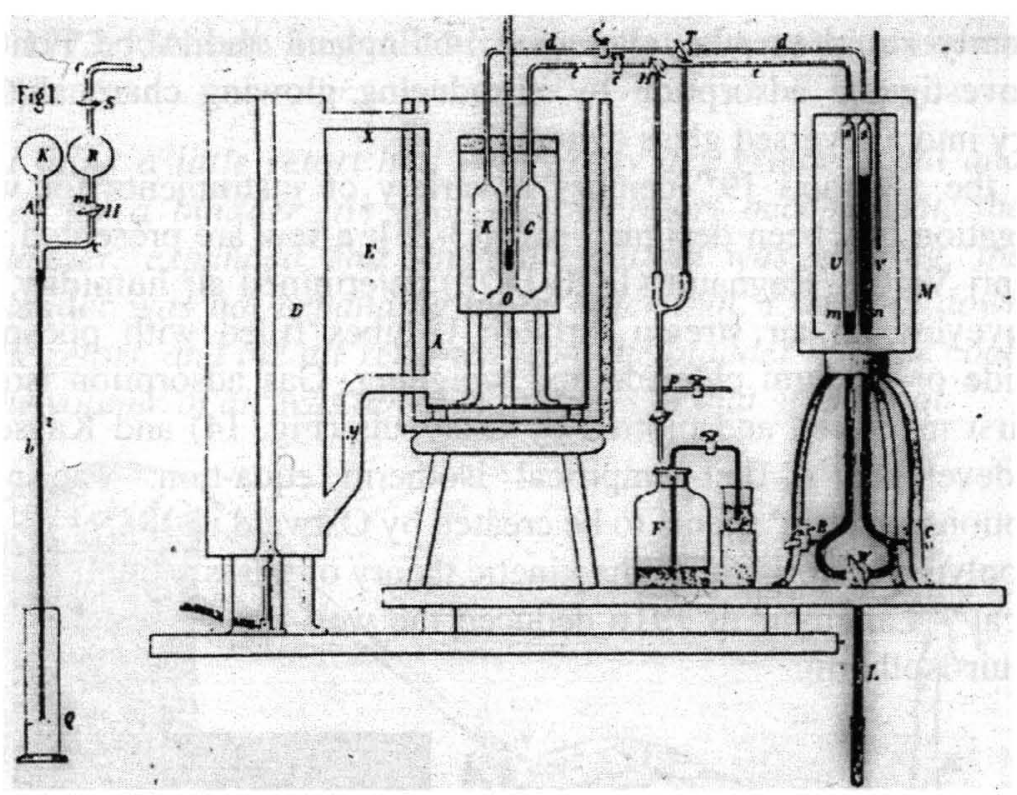

Fig. 14. P. Chappuis' sorption apparatus.

A first gravimetric apparatus for measurement of gas sorption isotherms was designed by Sandstede and Robens (Fig. 15) [36]. Today three methods are used to measure sorption isotherms: gravimetric, volumetric and gas chromatographic. Most widely applied is the volumetric method because here the expensive and sophisticated microbalance is avoided and because its operation in general is more simple. However, gravimetric methods provide some more detailed information. For hygrometry the special properties of water allow application of a variety of sensors and therefore a variety of very different instruments is offered. 


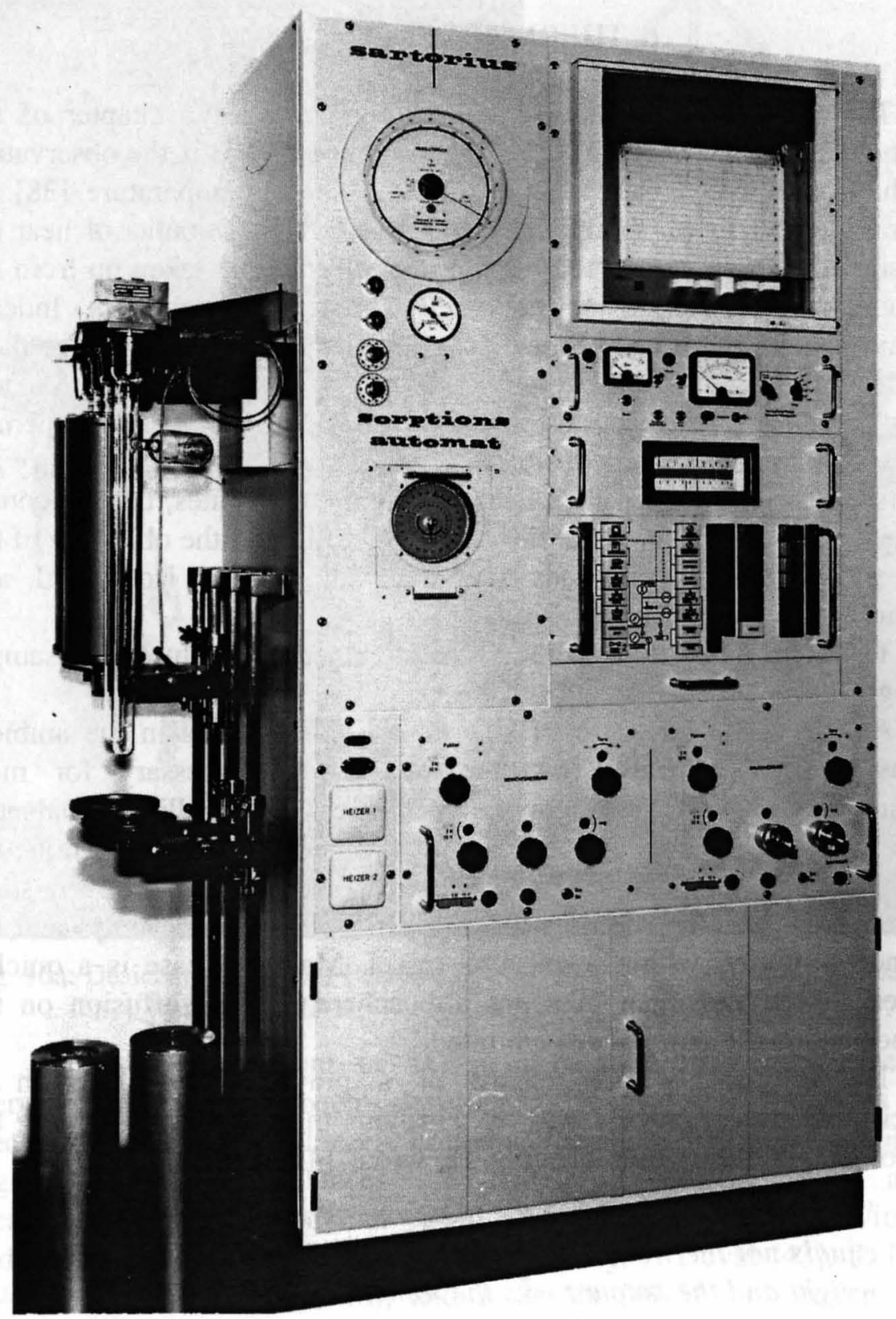

Fig. 15. Sartorius Gravimat, Automatic Sorption isotherms measu-ring apparatus with Gast vacuum microbalance on the left side. () Sartorius, Germany. 


\section{THERMOGRAVIMETRY}

The following text is essentially a summary of a chapter of the planned book 'Balances' [37]. Thermogravimetry (TG) is the observation of changes in mass as a function of time and/or temperature [38]. In contrast to real thermoanalytical methods in which amounts of heat are measured, in thermogravimetry the amount of material taken up from the surrounding gas phase or conveyed to it is determined. Indeed, thermogravimetry and calorimetry complement each other because there are reactions with heat evolution without evaporation of a volatile component and also reactions with evaporation and only small thermal effect. Unlike other chemical weighing processes in thermogravimetry the substance is not only weighed in its initial and end states, but the course of the reaction is followed continuously. According to the objective of the test, various working methods have evolved: isobaric, isothermal, and isobaric/isothermal [39-40].

Thermogravimetric apparatus are equipped with automatic sample changer.

As the partial pressure of evaporating components in the ambient atmosphere is generally low, vacuum is not necessary for most measurement tasks. Thermogravimetric devices with milligram balances were first developed from conditioning appliances used to determine the moisture content of textile fibres. In more recent times however, some thermogravimetric apparatus were supplied with vacuum pumps and the balance is placed within a vacuum vessel. Mass decrease is a quicker process in vacuum than in a gas atmosphere, as the diffusion on the surface and in the pores is not inhibited.

The presumably first record of a gravimetric observation of a thermo-chemical process was by Vitruvius in $27 \mathrm{BC}$ by observing the loss of weight during lime-burning. He wrote [41-42]:

"Whatever the weight of the limestone thrown into the kiln, it equals not the weight of that what comes out of it. But when weight and the amount was the same, one can observe that it lost about one third of its weight." 


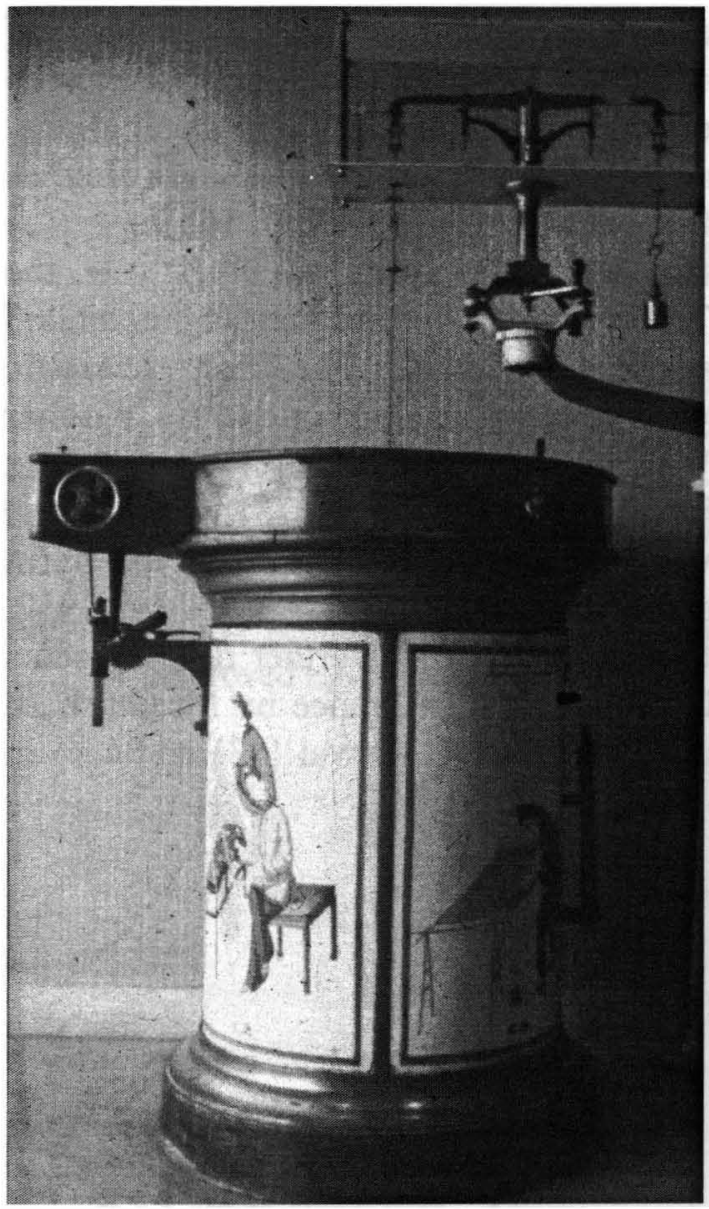

Fig. 16a. Désiccateur Talabot-Persoz-Rogeat, Lyon, France 1833.

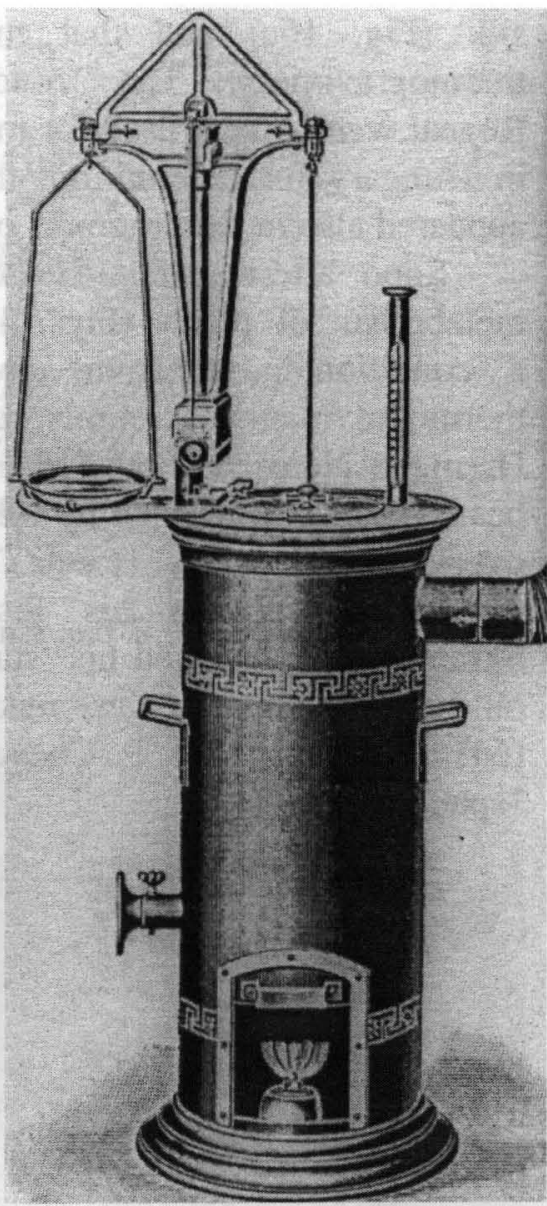

Fig. 16b. Conditioning apparatus Sauter, Germany.

The basic instrument of TG is a balance and many types of thermobalances have been developed. Today such balances are electromagnetic microbalances, covering the microgram and nanogram region. Suspension balances are favourable because they allow measurements with aggressive gases. The history of thermogravimetry and thermobalances is described extensively by C. Duval [43], S. Iwata [44-45], C.J. Keattch [46-48], and J. Šesták [49-51]. of Emich [52], Gorbach [53], Cunningham [54] and Behrndt [55]. A survey on commercially available instruments are included in the book of Mikhail and Robens [56] and in the planned book 'Balances' [37]. As discovered by $C$. Eyraud [48, 57-59] in 1833 the engineer Talabot equipped a laboratory at Lyon with thermobalances for quality control of Chinese 
silk (Fig. 16a) and that may be regarded as the beginning of thermogravimetry. The 'conditioning apparatus' of Talabot-PersozRogeat were widely used for moisture determination of any material, e.g. in Hungary for determining the moisture of wool. Such arrangements appeared also in the programs of scales manufacturers (Fig. 16b).

Soon afterwards such instruments were used to investigate the metabolism of plants (Figs. 17). In 1844 August Oertling exhibited a conditioning apparatus for silk at Berlin. The first scientific thermogravimetric assembly seems to have been described by Walther Hermann Nernst (1864 - 1941) and E.H. Riesenfeld in 1903: a quartz beam balance (improved by Julius Donau (*1877) (Fig. 18)) with electric oven. In $1915 \mathrm{~K}$. Honda was the very first to use the term 'thermobalance' for his instrument [60-61] (Fig. 19). In 1932, Škramowský presented his 'statmograph' [62-63]. Further developments on thermogravimetry were made in particular in France by M. Guichard [64], P. Dubois [65], P. Chevenard [66] and C. Duval [43] and also in Japan [44].
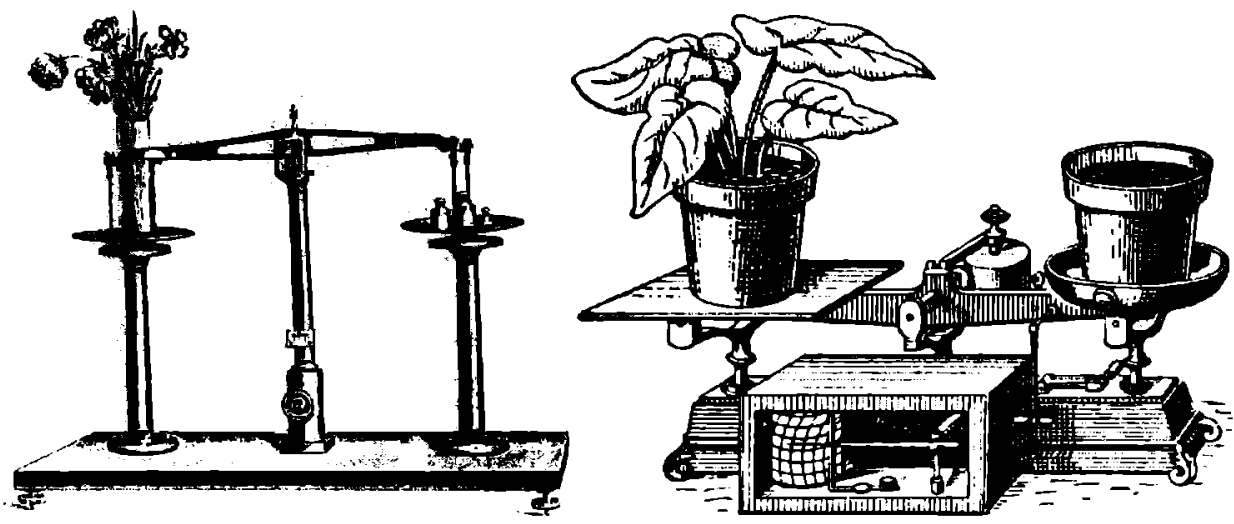

Fig. $17 \mathrm{a} / \mathrm{b}$. Conditioning balances for investigation of the metabolism of plants. 


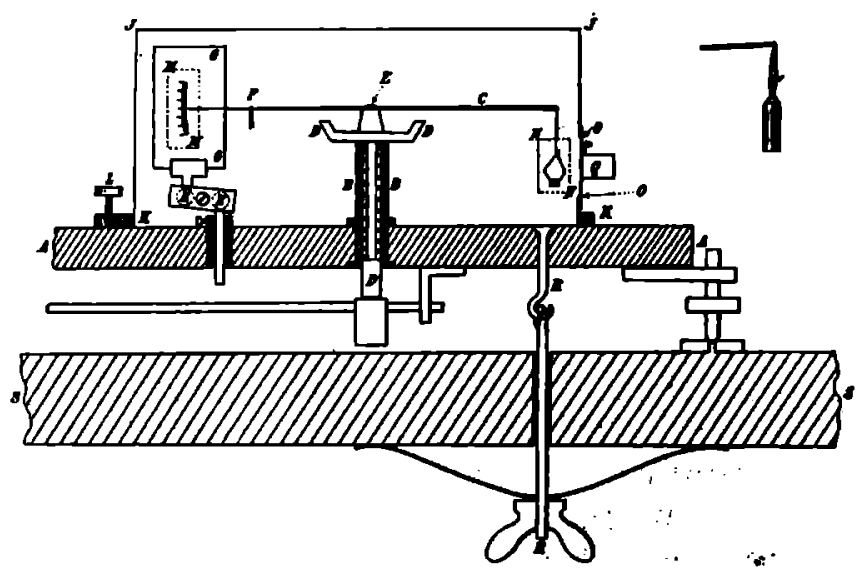

Fig. 18. Quartz beam balance of W. H. Nernst and E.H. Riesenfeld in 1903, improved by J. Donau.

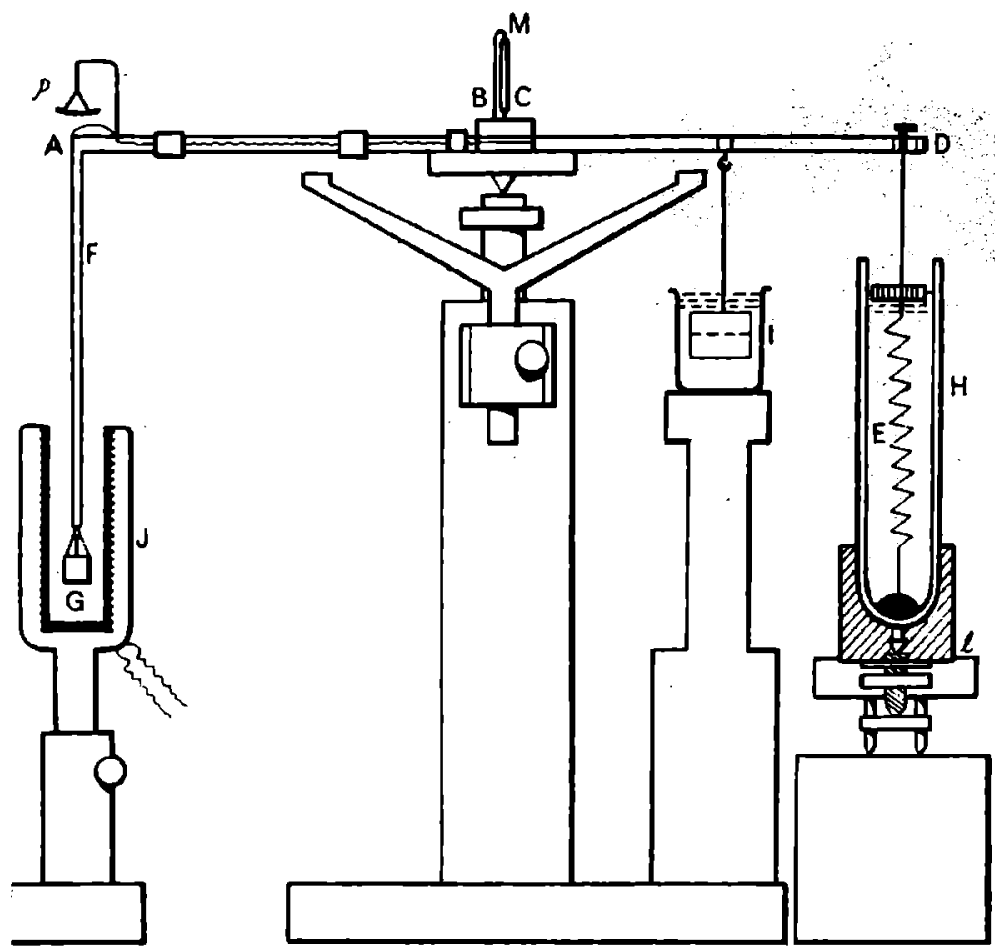

Fig. 19. K. Honda's thermobalance 1920, force compensation by a spring.

The first commercial thermobalance with electromagnetic force compensation was a conventional milligram balance, presented in 1953 by Charles Eyraud ( $\uparrow 2009)$ and Ivan Eyraud [67-68] and produced by the 
company A.R.A.M.ID.A.M./SETARAM of Lyon, France (Fig. 20). The deflection of the beam was detected by means of a photocell and compensated using a permanent magnet suspended at one side of the symmetric beam and forced by an electromagnetic field produced in coil surrounding the balance tube. For an improved model, the maximum load of the beam was up to $200 \mathrm{~g}$ and the range of electrical compensation up to $20 \mathrm{mg}$. In addition, up to $800 \mathrm{mg}$ could be placed by mechanical manipulators.

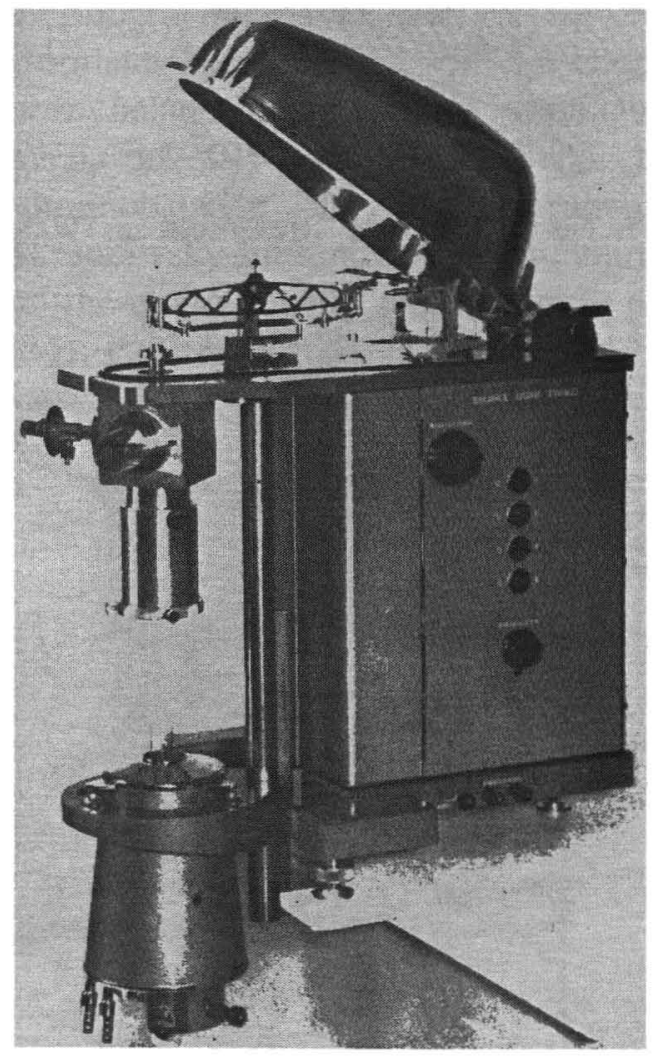

Fig. 20. Thermobalance of Charles Eyraud $(\dagger 2009)$ and Ivan Eyraud Lyon, France.

In 1953 W.A. de Kaiser developed the differential thermogravimetric method [69]. Important developments were made in Budapest (Hungary) by the brothers J. and F. Paulik [70-72], by G. Liptay [73] and others. J. Paulik and F. Paulik developed a universal thermogravimetric apparatus 'Derivatograph' [70, 72, 74-75], earlier produced by MOM, Budapest, Hungary, but still in use in many laboratories [76-80]. The apparatus allows for simultaneous calorimetric measurements and the balance can be used for dilatometry. Besides the original time-related mass decrease simultaneously the time-related differential curves are indicated. (Fig. 21). 

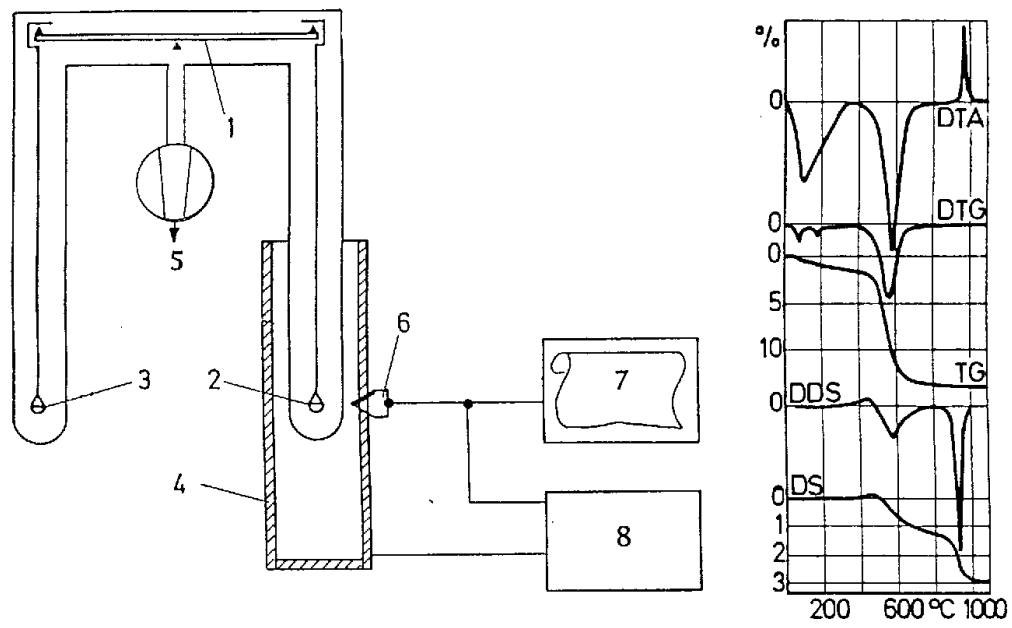

Fig. 21. Derivatograph of J. and F. Paulik. 1 balance, 2 sample, 3 counterweight, 4 programmed oven, 5 vacuum pump, 6 ther-mocouple, 7 recorder, 8 temperature program control, TG ther-mogravimetry, DTG differential thermogravimetry, DTA differ-rential thermal analysis, DS dilatometry, DDS differential dilatometry

Coats and Redfern [81] developed a method for the determination of kinetic data from non-isothermal thermogravimetry. Although the method is based on mathematical approximations and assumptions, it has been used successfully to determine activation energies of reactions [82-83].

The combination of the isothermal and the isobaric method in the quasi-isothermal method allows for the determination of thermodynamic data and the pore width distribution of porous materials. This method has been developed by F. Paulik [72] and P. Staszczuk [84-85]. Only with extremely fast-running reactions can measurements also be carried out at continually changing temperatures. Sorption enthalpies can be calculated from the temperature dependence of adsorption and absorption isotherms. The measuring method can be used to investigate catalytic processes and to determine phase plots.

For practical purposes thermogravimetry is combined with differential thermal analysis (DTA), as the same temperature program is run through with both methods. DTA can be carried out on the balance pan with a restriction on the sample mass or with a comparison sample next to the balance pan. The balance may also be used in dilatometry [7071]. Also a combination with calorimetry is sensible. It is an advantage if the gases released in thermogravimetry are analysed in gas chromatographs or mass spectrometers. However, since for optimal use of 
the different methods different sample size also is advantageous, separate apparatus used in parallel is favoured.

In the 1960s, AMINCO manufactured thermogravimetric apparatus with helical spring balances (Fig. 22). Ainsworth offered a series of apparatus with vacuum balances (Fig. 23).

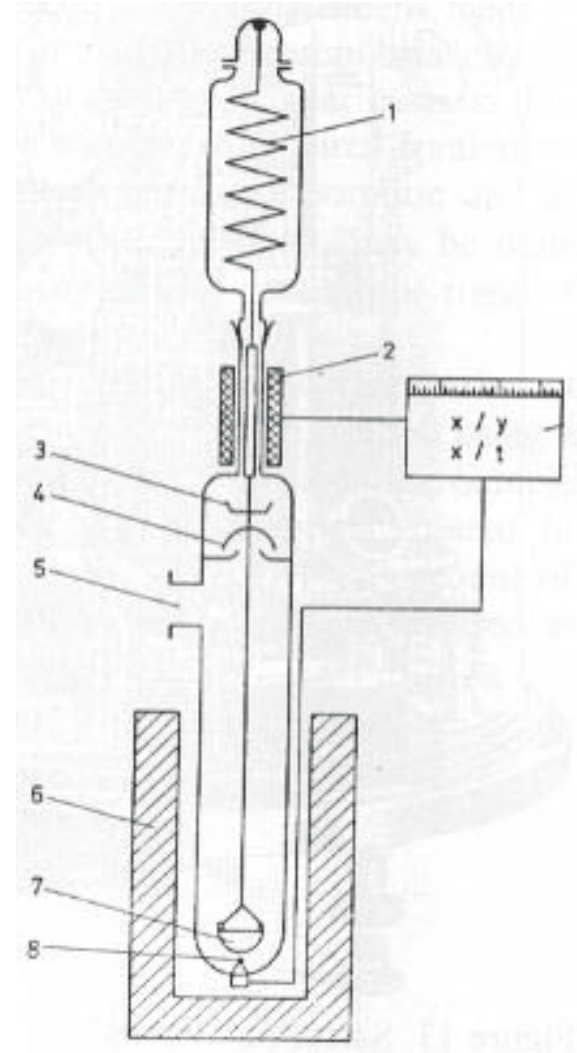

Fig. 22. AMINCO thermogravimetric apparatus.

Using micromechanical cantilevers as applied in micro-mechatronicsystems (MEMS) it is possible to investigate samples with nanogram mass and to observe mass changes in the pictogram range [86] (Fig. 24). The elastic lever is stimulated to mechanical vibrations. Observing the change of resonance frequencies the mass curve in dependence of increasing temperature can be registered. 


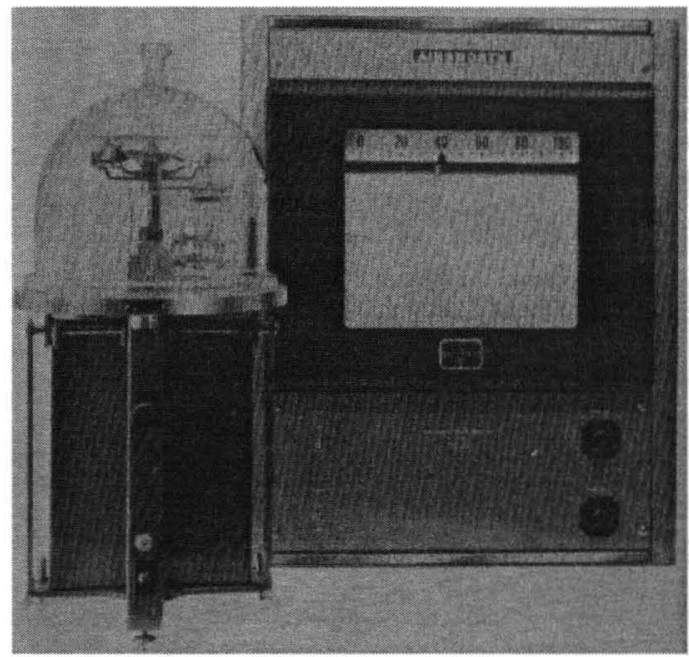

Fig. 23. Ainsworth vacuum balance. () Ainsworth.

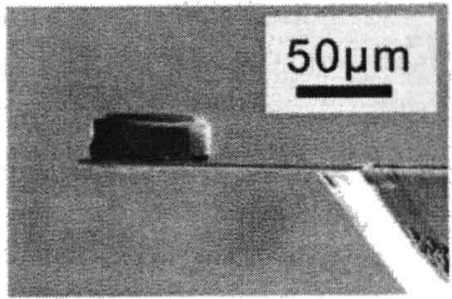

Fig. 24a. Micromechanical cantilever loaded with a zeolite single crystal sample.

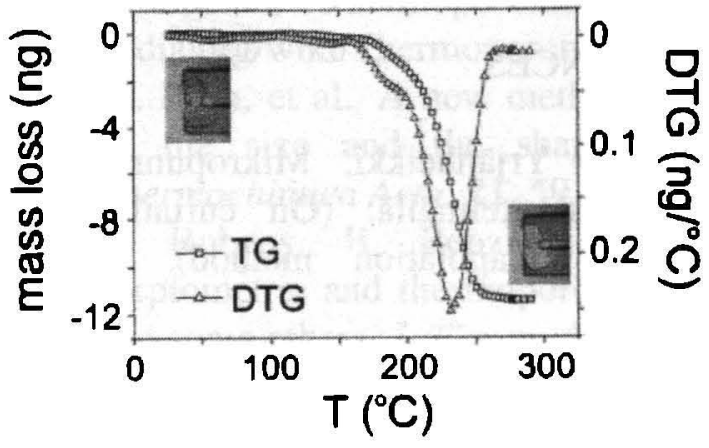

Fig. 24b. Heating of the sample, which results in a mass loss of $12 \mathrm{ng}$. In addition, the differrential mass loss (DTG) is plotted. (c) Rüdiger Berger. 


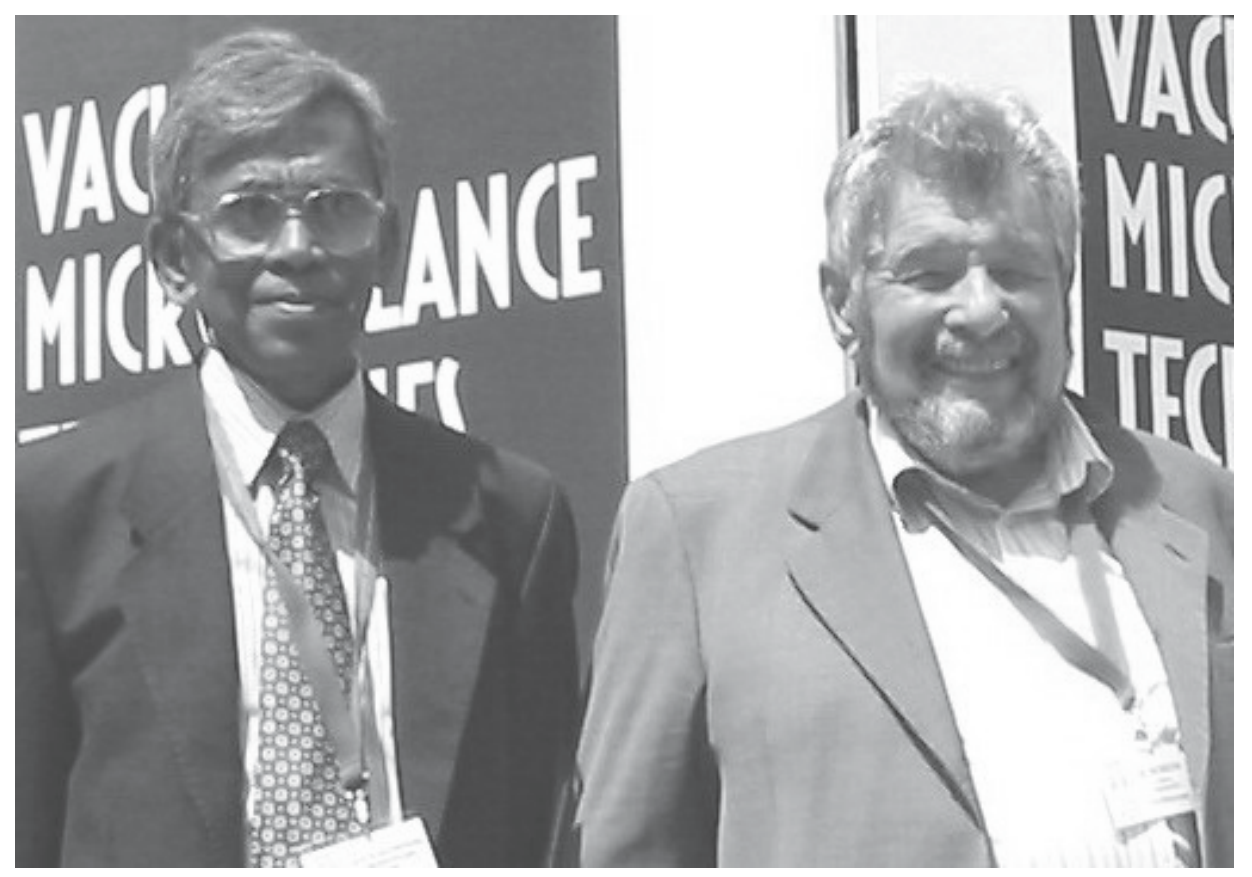

Shanath Amarasiri A. Jayaweera and Erich Robens at the International Conference on Vacuum Microbalance Techniques, June 29 - July 1, 2005, University of Technology, Wrocław, Poland.

\section{REFERENCES}

[1] O. Jäntti, J. Junttila, and E. Yrjänheikki, Mikropunnitusajan Lyhentämisestä Ekstrapolaatiomenetelmällä. (On curtailing the microweighing time by an extrapolation method), Suomen Kemistilehti, A 43, 214, (1970).

[2] O. Jäntti, J. Junttila, and E. Yrjänheikki, On curtailing the microweighing time by an extrapolation method, [in:] Progress in Vacuum Microbalance Techniques, (T. Gast and E. Robens, Eds.), Heyden: London. pp. 345-353, (1972).

[3] J.A. Poulis, et al., General application of Jäntti's method for the fast calculation of sorption equilibrium, J. Therm. Anal. Cal., 76(2), 583, (2004). 
[4] E. Robens, et al., Standardization of sorption measurements and reference materials for dispersed and porous solids, [in:] Adsorption and its Application in Industry and Environmental Protection. Vol. 1: Application in Industry, (A. Dabrowski, Ed.), Elsevier: Amsterdam. pp. 95-116, (1999).

[5] P. Klobes, and E. Robens, Standardization of the Pore Size Distribution. Particle \& Particle Systems Characterization, Particle \& Particle Systems Characterization, (2012).

[6] A. Tian, Bull. Soc.Chim. France, 33(4), 427, (1923).

[7] E. Calvet and C.R. Hebd. Seances Acad. Sci., 226,1702, (1948).

[8] E. Calvet and H. Prat, Récents Progrès en Microcalorimétrie, Paris Dunod, (1958).

[9] E. Calvet and H. Prat, Recent Progress en Microcalorimetry. Oxford: Pergamon Press, (1963).

[10] J.U. Keller and W. Zimmermann, Kinetic Analysis of Sensor-GasCalorimeters as Linear Passive Systems, (2000).

[11] L. Taylor, Electromagnetic Calorimeter. http://cms.web.cern.ch/ news/electromagnetic-calorimeter, Compact Moon Solenoid at Cern's LHC, (2011).

[12] M.R. Landry, Thermoporometry by differential scanning calorimetry: experimental considerations and applications, Thermochimica Acta, 433(1-2), 27, (2005).

[13] Wikipedia, Thermoporometry and cryoporometry. http://en.wikipedia.org/wiki/Thermoporometry_and_cryoporometry, (2012).

[14] M. Brun, et al., A new method for the simultaneous determination of the size and the shape of pores: The thermoporometry, Thermochimica Acta, 21, 59, (1977).

[15] E. Robens, B. Benzler, and K.K. Unger, Comparison of sorptometric and thermoporometric measurements on porous glass and some others, J. Therm. Anal. Cal., 56, 323, (1999).

[16] E. Robens et al., Gravimetric, Volumetric and Calorimetric Studies of the Surface Structure of Portland Cement, J. Therm. Anal. Cal., 62, 435, (2000).

[17] E. Robens et al., Investigation of characterizing methods for the microstructure of cement paste, Cement and Concrete Research, 32(1), 87, (2002).

[18] J. Mitchell et al., Nuclear Magnetic Resonance Cryoporometry, Phys. Rep., 461, 1, (2008).

[19] O.V. Petrov and I. Furo, NMR cryoporometry: Principles applications and potential, Prog. Nucl. Mag. Res. Sp., 54 (2), 97, (2009). 
[20] W.-J. 's Gravesande, Physices elementa mathematica, experimentis confirmata, sive introductio ad philosophiam Newtonianam, Leiden, (1720).

[21] W.-J. s'Gravesande and J.T.t. Desaguliers, Physices elementa mathematica, experimentis confirmata. English. Mathematical elements of natural philosophy, confirm'd by experiments, or, An introduction to Sir Isaac Newton's philosophy, fifth edition, 5 ed., London: J. Senex, W. Innys and R. Maney, and T. Longman, (1737).

[22] E. Robens et al., Measurement of water vapour sorption and humidity - A survey on measuring methods and standards, Annals of the Polish Chemical Society, 2 / II, 670, (2003).

[23] E. Robens et al., Water vapour sorption and humidtity - A survey on measuring methods and standards, [in:] Humidity Sensors: Types, Nanomaterials and Environmental Monitoring, (C.T. Okada, Ed.), Nova Science Publishers, Inc.: Hauppauge, NY. pp. 1-87, (2011)

[24] Bible, The Book of Judges., [in:] Bible. p. Chap. VI, vv. 33-40.

[25] D. Brunt, Ann. Rep. East Mailing Research Station, Kent, England for 1958, 41, (1959).

[26] C.H. Giles, Gideon's Fleece Test. The Earliest Recorded Vapor Phase Adsorption Experiment?, J. Chem. Education, 39, 584, (1962).

[27] E. Gerland and F. Traumüller, Geschichte der physikalischen Experimentierkunst, Leipzig, (1899).

[28] N. Cusanus, Idiota de Staticis Experimentis, Dialogus, Codex Cusanus 1456/64, Straßburg Folio, 135r, (1450).

[29] L.B. Alberti, L'architettura, Padua, Firenze, (1483/1485)

[30] L. da Vinci, Codex atlanticus - Saggio del Codice atlantico, (Aretin, Ed.), vol. fol. 249 verso-a + fol. 8 verso-b., Milano, (1872).

[31] L. da Vinci, Catalogue "Les Mots dans le Dessin" of the Cabinet des Dessin, Paris Louvre, (1986).

[32] E. Robens and A. Dąbrowski, Extension of the measuring range of balances, J. Therm, Anal. Cal., 86(1), 17, (2006).

[33] E. Robens and K. Rübner, Gravimetrische Wasserdampfsorptionsund Feuchtemessung an Feststoffen, GIT Z. Labortechnik, 47(10), 1046, (2003).

[34] E. Robens et al., Measurement of water vapour sorption and humidity. A survey on measuring methods and standards, ICTAC News, 38 (1), 39, (2005). 
[35] R. Wernecke, Industrielle Feuchtemessung, Weinheim: Wiley $\mathrm{VCH},(2003)$.

[36] G. Sandstede and E. Robens, Automatisierte Apparatur zur gravimetrischen Bestimmung der spezifischen Oberfläche und der Porengröße, Chem.-Ing.-Tech., 34(10), 708, (1962).

[37] E. Robens, S.A.A. Jayaweera, and S. Kiefer, Balances Instruments, Manufacturers, History, Heidelberg: Springer, (2013).

[38] W.F. Hemmingerand H.K. Cammenga, Methoden der thermischen Analyse, Heidelberg: Springer, (1989).

[39] E. Robens and G. Walter, Thermogravimetrische Arbeitsmethoden. Sprechsaal, 104(10), 426, (1971).

[40] E. Robens and G. Walter, Thermogravimetrische Arbeitsmethoden. Sprechsaal, 104(11), 489, (1971).

[41] M. Vitruvius Pollio, De Architectura, Vol. II/III. 33 - 14 BC, Rome.

[42] R.C. Mackenzie, Thermochimica Acta, 75, 251, (1984).

[43] C. Duval, C, Inorganic Thermogravimetric Analysis, (1953), Amsterdam: Elsevier, 1961.

[44] S. Iwata, Über die Entwicklung der Thermowaage, besonders in Japan, Bonn: Chemischen Institut der Universität Bonn, (1961).

[45] S. Iwata, Soil-Water Interaction, $2^{\text {nd }}$ ed., New York: Dekker, (1995).

[46] C.J. Keattch, An Introduction to Thermogravimetry, London: Heyden/Sadtler, (1969).

[47] C.J. Keattch, The History and Development of Thermogravimetry, University of Salford: Salford, (1977).

[48] C.J. Keattch, Studies in the history and development of thermogravimetry, J. Therm, Anal. Cal.,44(5), (1995).

[49] J. Šesták, P. Hubík, and J.J. Mareš, Historical roots and development of thermal analysis and calorimetry, in Glassy, Amorphous and Nano-Crystalline Materials: Thermal Physics, Analysis, Structure and Properties, (J. Šesták, P. Hubík and J.J. Mareš, Eds.), Springer: Dordrecht, (2011).

[50] P. Holba and J. Šesták, Czechoslovak footprints in the development of methods of thermometry, calorimetry and thermal analysis, Ceramics - Silikáty, 56(2), 159, (2012).

[51] J. Šesták, Some historical aspects of thermal analysis: Origins of THERMANAL and ICTA, Thermanal, 1, (2005). 
[52] F. Emich, Einrichtung und Gebrauch der zu chemischen Zwecken verwendbaren Mikrowaagen., [in:] Handbuch der biochemischen Arbeitsmethoden., (E. Abderhalden, Ed.), Berlin/Wien. pp. 55-147, (1919).

[53] G. Gorbach, Die Mikrowaage, Mikrochemie, 20(2/3), 254, (1936).

[54] B.B. Cunningham, Microchemical methods used in nuclear research, Nucleonics, 5(5), 62, (1949).

[55] K.H. Behrndt, Die Mikrowaagen in ihrer Entwicklung seit 1886. Z. angew. Physik, 8(9), 453, (1956).

[56] R.S. Mikhail and E. Robens, Microstructure and Thermal Analysis of Solid Surfaces, Chichester: Wiley, (1983).

[57] C. Eyraud. and P. Rochas, Thermogravimetry and silk conditioning in Lyons. A little known story, Thermochimica Acta, 152, 1, (1989).

[58] W.F. Hemminger and K.-H. Schönborn, A nineteenth century thermobalance, Thermochimica Acta, 39, 321, (1980).

[59] C. Eyraud, E. Robens, and P. Rochas, Some comments on the history of thermogravimetry, Thermochimica Acta, 160, 25, (1990).

[60] K. Honda, On a Thermobalance. Science Reports of the Tôhoku University, Sendai Serie 1, 4, 97, (1915).

[61] K. Honda, Kinzoku no Kenkyu, 1, 543, (1924).

[62] F. Sabadvary and B.-G. E., J. Therm, Anal., 389, (1979).

[63] J. Šesták and J.J. Mares, From Caloric to Statmograph and polarography, J. Therm, Anal., 88(3), 1, (2007).

[64] M. Guichard, Bull. Soc. Chim. France, 33, 258, (1923).

[65] P. Dubois, Bull. Soc. Chim. France, 3, 1178, (1935).

[66] P. Chevenard, X. Waché, and R. de la Tullaye, Bull. Soc. Chim. France, 10, 41, (1944).

[67] C. Eyraud and I. Eyraud. Catalogue, [in:] 50e Expos. Soc. Fr. Physique, (1953).

[68] C. Eyraud and I. Eyraud, Laboratoires, 12, 13, (1955).

[69] W.A. de Keyser, Nature, 172, 364, (1953).

[70] J. Paulik and F. Paulik, Thermal Analysis, Part A: Simultaneous Thermoanalytical Examinations by Means of the Derivatograph, Thermal Analysis, (W.W. Wendlandt, Ed.), Amsterdam: Elsevier, (1981).

[71] J. Paulik and F. Paulik, Simultaneous thermoanalytical examination by means of the Derivatograph, [in:] Comprehensive Analytical Chemistry (W.W. Wendlandt, Ed.), Elsevier Amsterdam, (1981).

[72] Paulik, F., Special Trends in Thermal Analysis. 1995, Chichester: Wiley. 
[73] G. Liptay, Atlas of Thermoanalytic Curves, Budapest, London: Akadémiai Kiadó and Heyden, 1971-1977,.

[74] F. Paulik, J. Paulik, and L. Erdey, Der Derivatograph. 1. Mitteilung, Z. Anal. Chem., 160, 241, (1957).

[75] F. Paulik, J. Paulik, and L. Erdey, Z. Anal. Chem.,160, 241, (1958).

[76] P. Staszczuk, Physicochemical properties of liquid-solid interfaces by means of controlled rate thermal analysis, Thermochimica Acta, 247, 169, (1994).

[77] J. Goworek and W. Stefaniak, Investigation on the porosity of silica gel by thermal desorption of liquids, Mat. Chem. Phys., 32, 244, (1992).

[78] J. Goworek and W. Stefaniak, Study of the porosity of carbonaceous materials and organic polymers by thermal analysis, J. Therm, Anal., 51, 541, (1998).

[79] J. Goworek and W. Stefaniak, A comparison of nitrogen adsorption data and thermogravimetric methods in the assessment of the pore size distribution of mesoporous silica gels, Journal of Porous Materials, 3, 121, (1996).

[80] P. Staszczuk, The studies of the heterogeneous properties of solid surfaces by means of the Derivatograph Q-1500D, J. Therm. Anal. Cal., 53, 597, (1998).

[81] A.W. Coats and J.P. Redfern, Nature, 201, 68, (1964).

[82] H. Barkia, H.L. Belkbir, and S.A.A. Jayaweera, Thermal analysis studies of oil shale residual carbon. J Thermal Analysis and Calorimetry, 2004. 76: p. 615-622.

[83] T. Berrajaa et al., Thermal analysis studies of the pyrolysis of Tarfaya oil shale, [in:] Carbon '88 (B. McEnaney and T.J. James, Eds.), pp. 567-569, (1988).

[84] P. Staszczuk and D. Glazewski, Study of heterogeneous properties of solids by means of a special thermal analysis techniques, $J$. Therm. Anal. Cal., 55, 467, (1999).

[85] P. Staszczuk, et al., Total heterogeneity of Al2O3 surface, J. Therm. Anal. Cal., 71(2), 445, (2003).

[86] R. Berger, J. Gutmann, and R. Schäfer, Scanning probe methods: From microscopy to sensing, Bunsen Magazin, 2, 42, (2011). 